\title{
KNOWLEDGE AUDIT FRAMEWORK : A CASE STUDY OF THE MALAYSIAN ELECTRICITY SUPPLY INDUSTRY
}

\author{
Sulfeeza Mohd Drus, Siti Salbiah Mohamed Shariff \& Marini Othman \\ Department of Information Systems \\ Universiti Tenaga Nasional, Malaysia
}

sulfeeza@uniten.edu.my; sitisalbiah@uniten.edu.my; marini@uniten.edu.my

\begin{abstract}
Literature has concurred that knowledge audit promotes efficient management and exploitation of organizational knowledge. Due to the distinctive business environment of the electricity supply industry, the existing knowledge audit frameworks may not be suitable to be adopted 'as-they-are' by the industry. In this context, this research has proposed a knowledge audit framework that is specifically tailored to the environment of the electricity supply industry. Two main electricity companies in Malaysia were selected as the case companies for this research. The proposed knowledge audit framework aims to present a holistic way of assessing and analyzing the current knowledge environment of the electricity supply industry in Malaysia. The outcomes of the knowledge audit exercise could be used in developing a knowledge strategy that is aligned with the business strategies of the electricity companies.
\end{abstract}

Keywords: Knowledge audit, knowledge management, knowledge strategy, electricity supply industry.

\section{INTRODUCTION}

The global economy has shifted towards greater reliance on the utilization and exploitation of intangible assets, such as information as well as knowledge related resources (Alavi \& Leidner, 2001; Nonaka, 1994; Singh, 2007), which have triggered the notion of knowledge as the strategic commodity in the new economy. This scenario initiates the conception of knowledge economy, 
which is defined as "production and services based on knowledge-intensive activities that contribute to an accelerated pace of technical and scientific advance, as well as rapid obsolescence" (Powell \& Snellman, 2004). As such, knowledge provides the means of creating innovative products and services, which must be well-protected and safeguarded from external leakages (Choi, Poon, \& Davis, 2008; du Plessis, 2005; McBriar et al., 2003).

In line with this global economic transformation, the Malaysian government has also embarked on several initiatives such as the Knowledge-Based Economy Master Plan, the National IT Agenda (NITA) and the Multimedia Super Corridor (MSC) in preparation towards becoming a knowledge-based economy nation. According to Jaafar (2002), the establishment of MSC is aimed "to accelerate Malaysia's entry into the Information Age, and help realize Vision 2020." It is also hoped that, by attaining the knowledge-based economy status, Malaysia is able to achieve sustainable rapid economic growth and competitiveness (Economic Planning Unit [EPU], n.d.). Towards this end, a reliable, stable and affordable telecommunication, electricity, water and transportation infrastructure are all seen as vital to assisting Malaysia towards realizing this goal.

As one of the most essential types of utilities, electricity plays an important role in ensuring that Malaysia is able to fulfil its aim of attaining the knowledge-based economy status. Literature by Choy (2005), Mohamed and Lee (2006), and Ong, Mahlia and Masjuki (2011) explain that a stable, economical and abundant supply of electricity is the catalyst of a modern economic development. Mohamed and Lee (2006) assert that "globally, per capita consumption of energy is often used as a barometer to measure the level of economic development in a particular country." This situation is evident in Malaysia, as the electricity consumption per capita moves in tandem with the increasing gross domestic product (GDP) of the country from 2001 to 2011 (EPUa, n.d.).

Due to the significant role of the electricity supply industry (ESI) in the Malaysian economic landscape, it is prudent and essential for the players in the industry such as the electricity companies to create, capture, share and utilize quality knowledge for their strategic and operational purposes. Thus, efficient and effective management of organizational knowledge is a must to ensure that quality knowledge is recognized, appreciated, manipulated and stored for the benefits of electricity companies. 


\section{RESEARCH BACKGROUND}

Numerous organizations have embarked on initiatives in streamlining the activities and processes related to the creation, management and exploitation of organizational knowledge (BenMoussa, 2009; Hicks et al., 2007). In the broadest context, these activities and processes are known as knowledge management $(\mathrm{KM})$. Generally, KM can be regarded as the process of generating enduring value from organizational intellectual capital or knowledge-based assets (Alavi \& Leidner, 2001; Singh, 2007). There are four (4) KM processes, namely knowledge creation, knowledge storage and retrieval, knowledge distribution, and knowledge application (Alavi \& Leidner, 2001). These four (4) processes are supported by three (3) different components: people, technology and process. According to Bhatt (2000), 70\% of the efforts focus on the people aspect, followed by process $(20 \%)$ and technology $(10 \%)$. Therefore, it can be deduced that in ensuring that KM initiatives succeed, an organization should put more emphasis on the people aspect in the KM processes as compared to the technological aspect.

Before organizations embark on any KM initiatives, they have to understand their current situation and only then they would be able to devise a strategy that better reflects their knowledge needs. Cooper, Peszynski and Molla (2008) assert that one of the critical success factors for knowledge strategy (KS) is to understand the core business processes and the knowledge environment of an organization. This can be achieved by assessing the current knowledge environment through conducting a knowledge audit (KA). Rahman and Shariff (2009) also state that by assessing existing knowledge in an organization, a KS that reflects the requirements of the organization can be devised.

According to BenMoussa (2009), several organizations have yet to see the positive results of the investment in KM initiatives. Various literature argue that the failure of many $\mathrm{KM}$ initiatives are due to the exclusion and omission of KA as one of the essential preliminary processes or activities in KM initiatives (Liebowitz et al., 2000; Hylton, 2005; Jurinjak \& Klicek, 2008). According to Hylton (2005), "knowledge audit is the indisputable first step in a knowledge management initiative. Yet, it has not been sufficiently recognized as being of paramount importance to any and every knowledge management undertaking." This view is also seconded by Liebowitz et al. (2000) who emphasize that enforcement of KA is one of the few critical first steps in any KM activity.

A review of published literature shows that numerous studies have been conducted in the KA domain by researchers such as Liebowitz et al. (2000), 
Burnett, Illingworth and Webster (2004), Perez-Soltero et al. (2006), Jurinjak and Klicek (2008), Gourova, Antonova and Todorova (2009), Levy, Hadar and Aviv (2009), and Leung et al. (2010). However, most of these studies only propose generic KA frameworks and provide high-level details on the phases or requirements of KA exercise (Mohd Drus \& Shariff, 2011). It may not be possible for organizations to adopt such frameworks instantaneously.

Furthermore, these studies do not investigate the relationship or interdependencies among the KM, KA and KS processes. A comprehensive perspective of the inter-connection among the KM, KA and KS processes will help organizations to reap maximum benefits as well as add value, both in terms of minimizing knowledge loss and optimizing knowledge resources as they will be able to comprehend "where are you now?" - by the conducting the KA process; "where do you want to be?" - by devising the KS process based on the KA process outcomes; and lastly "how do you get there?" - by implementing suitable KM tools and technologies (as shown in Figure 1).

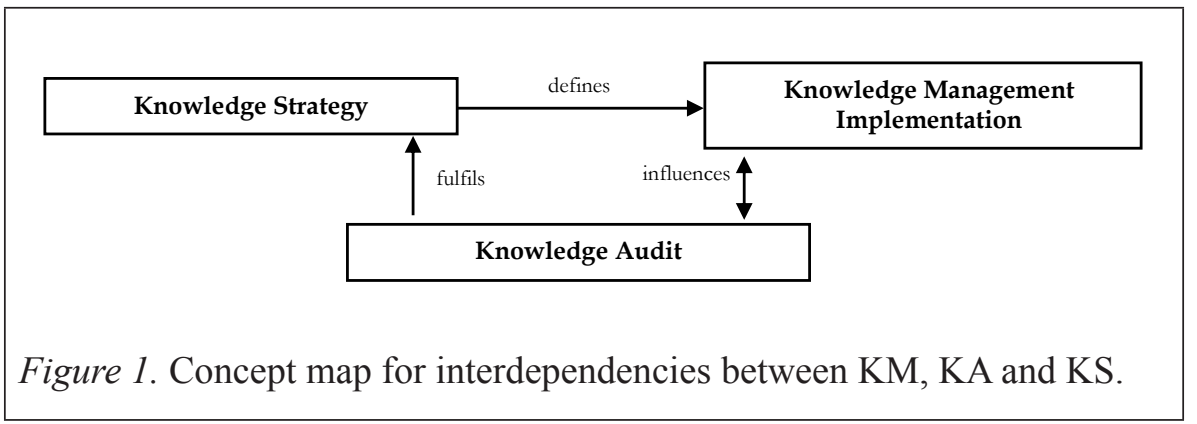

A study by Rahman and Shariff (2009) indicates that government-linked companies (GLCs) in Malaysia that have undertaken KM initiatives tend to be more innovative. As the companies operating in the electricity supply industry (ESI) in Malaysia are mainly GLCs, an efficient and effective KM process implementation is considered imperative for them to become more innovative. Knowledge gained by these employees throughout their stay with the electricity companies, such as those employees who have acquired it through field experience, is considered difficult to be learned from manuals or imitated by those who have not experienced it. Due to this, electricity companies in Malaysia must take a proactive effort in ensuring that this realized tacit knowledge will be retained by the companies. This valuable knowledge will be otherwise lost if the employees decide to leave the company. Keeping this in mind, this research aims to focus on developing a KA framework that suits the business environment of ESI that will help them to assess "where they are now". Such a framework, when developed, could be used in formulating 
the most suitable strategy for managing their organizational knowledge and identifying the appropriate KM tools and technologies for retaining, sharing and collecting knowledge.

\section{RESEARCH METHOD}

This research adopted a case study using the single-case design with concurrent mixed-method as the strategy of inquiry. Two (2) main electricity companies in Malaysia were chosen as the primary case companies for this research. Semi-structured, open-ended interviews and survey questionnaires were used as the data collection methods for this research. The interview participants and survey respondents for this research were selected based on the selective and purposeful sampling method. According to Patton (2002), the selected sample should be information rich cases where one can learn a great deal about issues of central importance to the purpose of the research. For this research, several departments from the main business units of the case companies were selected as participants. The rationale and justification for selecting these departments are as follows:

- $\quad$ The selected business units perform the core business functions of the company. Thus, the knowledge contained in these business units are critical to the operations of the company.

- $\quad$ The selected departments in the identified business units perform the core functions of the unit, and/or formulate the strategies and directions for the case companies.

A total of nine (9) participants, representing the main core functions of the case companies were interviewed. The participants interviewed were the heads of department. Hence, they were able to provide in-depth explanations on the current approaches in managing, sharing, exploiting and assessing the current organizational knowledge that is deemed critical for their business operations. The survey questionnaires were distributed to a total of 180 respondents. The response rate was $46.7 \%$. The responses from the survey questionnaires aided this research in assessing the respondents' perspectives on the importance and benefits of effective management of knowledge in their organizations as well as their involvement in the related KM activities. Since there is insufficient literature and studies of knowledge audit in the Malaysian ESI context at this juncture, it was deemed that the inductive approach was the most suitable strategy to be adopted for analyzing the data collected for this research (Lauri \& Kyngas ; 2005). 


\section{ANALYSIS}

In order to better understand how the case companies manage their organizational knowledge, the implementation and practices of $\mathrm{KM}$ in the case companies were enquired via a survey questionnaire. $45.2 \%$ of the respondents answered that their companies had implemented and practised KM. The higher percentage of $54.8 \%$ responses from the respondents which indicated that their companies had yet to implement KM may well imply the absence of a formal enterprise-wide KM initiative in the case companies. Furthermore, for the respondents who indicated that their companies had already implemented and practised KM, only $36 \%$ were involved directly in the KM projects or initiatives in their companies. Table 1 shows the mean value obtained for implementing and practising KM in the case companies. The Cronbach's coefficient alpha reading acquired is 0.94 which is considered as being a good indicator to test the consistency of the respondents' answers to all the factors and scales that are used in the measure. A four-point Likert scale ranging from ' 1 ' which means 'Not Important At All' to ' 4 ' which means 'Very Important' was used to test the items. The results revealed that all the three groups of respondents (based on their current positions) had similar opinions and agreement on the reasons for implementing and practising KM. The ANOVA tests indicated that there were no statistically significant differences on the factors in the levels of importance (mean score) on the reasons for implementing and practising KM by the different groups of respondents (i.e. management, executives and non-executives) at a $5 \%$ level of significance. High $\mathrm{p}$ values can be observed in a few factors. They are: reduce information overload, capture and reuse best practices, reduce exposure to risk and improve employees' skills and knowledge (i.e. these factors have $\mathrm{p}$ values greater than 0.5 ). Thus, it can be presumed that the respondents had statistically significant similar opinions on the above mentioned factors.

Table 1

Mean Score for Implementing and Practicing KM in Case Companies

\begin{tabular}{|c|c|c|c|c|}
\hline \multirow[t]{2}{*}{ Factor } & \multicolumn{3}{|c|}{ Mean score } & \multirow{2}{*}{$\begin{array}{c}\text { ANOVA } \\
\text { Sig. } \\
\mathrm{p}<0.05\end{array}$} \\
\hline & Management & Executive & $\begin{array}{l}\text { Non- } \\
\text { Executive }\end{array}$ & \\
\hline $\begin{array}{l}\text { To improve employees' skills and } \\
\text { knowledge }\end{array}$ & 2.88 & 2.92 & 4.00 & 0.526 \\
\hline $\begin{array}{l}\text { To protect loss of knowledge when } \\
\text { employees resign or retire }\end{array}$ & 3.13 & 2.62 & 3.50 & 0.435 \\
\hline
\end{tabular}

(continued) 


\begin{tabular}{lcccc}
\hline \multicolumn{1}{c}{ Factor } & \multicolumn{3}{c}{ Mean score } & \begin{tabular}{c} 
ANOVA \\
Sig. \\
\cline { 2 - 3 }
\end{tabular} \\
\cline { 2 - 3 } & Management & Executive & $\begin{array}{c}\text { Non- } \\
\text { Executive }\end{array}$ & p.05 \\
\hline $\begin{array}{l}\text { To identify knowledge that is present and } \\
\text { available in the company }\end{array}$ & 2.75 & 2.73 & 4.00 & 0.398 \\
$\begin{array}{l}\text { To identify knowledge that is required } \\
\text { but not available in the company }\end{array}$ & 2.63 & 2.65 & 4.00 & 0.357 \\
$\begin{array}{l}\text { To reduce information overload } \\
\text { To use knowledge to meet company's }\end{array}$ & 2.00 & 2.12 & 2.50 & 0.864 \\
objectives and goals & 2.75 & 2.77 & 4.00 & 0.337 \\
$\begin{array}{l}\text { To promote knowledge sharing in the } \\
\text { company }\end{array}$ & 3.00 & 2.65 & 4.00 & 0.302 \\
To capture and reuse best practices & 2.88 & 2.85 & 3.50 & 0.795 \\
To gain advantage over the competitors & 2.75 & 2.65 & 4.00 & 0.390 \\
To reduce exposure to risk & 2.75 & 2.73 & 3.50 & 0.692 \\
To improve quality & 2.75 & 2.65 & 4.00 & 0.390 \\
To reduce costs & 2.38 & 2.69 & 4.00 & 0.272 \\
To accelerate innovation & 2.50 & 2.69 & 4.00 & 0.281 \\
To boost revenue & 2.13 & 2.65 & 4.00 & 0.272 \\
To increase added values for customers & 2.63 & 2.50 & 4.00 & 0.354 \\
\hline & & & & \\
\hline
\end{tabular}

Despite the lack of a formal method in the case companies to manage their organizational knowledge, most of the participants interviewed were able to give fair definitions of knowledge management (KM). Their answers indicated that the participants interviewed had some fundamental understanding of KM (as shown in Table 2). Thus, it can be reckoned that although KM is being practiced and implemented in a restricted manner in the case companies, the $\mathrm{KM}$ process is not an unfamiliar or new concept to the interview participants.

\section{Table 2}

Definitions of KM (by interview participants)

\begin{aligned} & \hline Participant \multicolumn{1}{c}{ Definition of KM } \\ & \hline Participant 1 $\begin{array}{l}\text { How knowledge is managed in the company by making it accessible to } \\ \text { everybody; how knowledge is utilised to increase, maintain and retain staff } \\ \text { knowledge. }\end{array} \\ &$ Participant 2 How to manage, utilise and optimise knowledge in the working environment. \\ & Participant 3 $\begin{array}{l}\text { KM consists of two (2) components, which are (a) organising knowledge in } \\ \text { such a way that can be beneficial to the employee to use and (b) retaining } \\ \text { organisational knowledge that is valuable. }\end{array} \\ &$\hline\end{aligned}




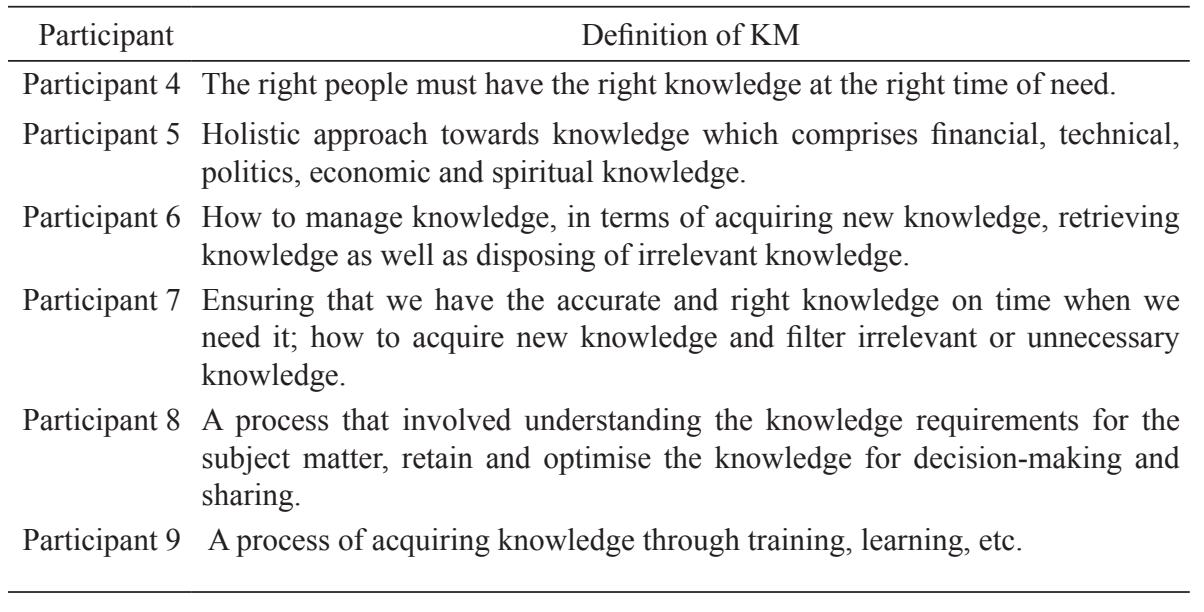

Based on the definitions obtained from them, it can be summarized that KM is defined as (a) a holistic approach towards acquiring, managing, utilizing and optimizing knowledge, and (b) a process of understanding the knowledge requirement and how to acquire, retain and optimize knowledge for decisionmaking.

Despite the restricted implementation and practices in the case companies, $\mathrm{KM}$ is deemed beneficial to the companies. Table 3 shows the mean score of the perceived benefits for implementing and practising $\mathrm{KM}$ in their companies. The Cronbach's coefficient alpha obtained was 0.92 . The results revealed that all three groups of respondents (based on the current position) had similar opinions and agreement on the perceived benefits of implementing and practising $\mathrm{KM}$ in their companies. High $\mathrm{p}$ values (i.e. these factors have $\mathrm{p}$ values greater than or equivalent to 0.5 ) can be observed in a few factors such as improved innovation, improved work routines and increased sharing, showing significant similarity among the different job levels. Thus, it can be presumed that these factors listed as the perceived benefits of KM implementation in the case companies are deemed statistically as being similarly significant to the respondents.

Nevertheless, despite the high agreement on the perceived benefits of the KM initiatives in the case companies, the respondents did face some problems and challenges in implementing and practising $\mathrm{KM}$ in their companies. As depicted in Table 4, the mean score by management, executives and nonexecutives on the challenges and problems that they faced in implementing and practising KM in their companies shows statistically substantial similarity. The Cronbach's coefficient alpha obtained was 0.99 for the factors listed as the challenges and problems in KM implementation in the case companies. 
Table 3

Mean Score for Perceived Benefits of KM Initiatives in Case Companies

\begin{tabular}{lcccc}
\hline Perceived benefits of KM initiative & \multicolumn{3}{c}{ Mean score } & $\begin{array}{c}\text { ANOVA } \\
\text { Sig. p<0.05 }\end{array}$ \\
\cline { 2 - 4 } & Management & Executive & $\begin{array}{c}\text { Non- } \\
\text { Executive }\end{array}$ & \\
\hline Better decision-making & 3.00 & 2.73 & 4.00 & 0.368 \\
Improved work routines & 3.00 & 2.62 & 3.50 & 0.525 \\
Improved employees' skills & 2.88 & 2.88 & 4.00 & 0.260 \\
Improved connection and & 2.75 & 2.69 & 4.00 & 0.382 \\
communication with the experts & 2.88 & 2.69 & 4.00 & 0.387 \\
Improved client/customer relation & 3.13 & 2.88 & 4.00 & 0.500 \\
Increased sharing of knowledge within & 2.25 & 2.73 & 3.50 & 0.418 \\
the company & 2.38 & 2.88 & 4.00 & 0.272 \\
Increased employee retention & 2.63 & 2.54 & 3.50 & 0.612 \\
Increased teamwork & 2.63 & 2.69 & 4.00 & 0.354 \\
Improved innovation & 2.25 & 2.73 & 3.50 & 0.418 \\
Improved employees' satisfaction & & &
\end{tabular}

The results showed that all three groups of respondents (based on their current positions) had similar opinions and agreement on the challenges and problems that they faced in implementing and practising KM in their companies. The ANOVA tests indicated that there were no statistically significant differences on the level of importance (mean score) on the reasons for implementing and practising KM by the different groups of respondents (i.e. management, executives and non-executives) at 5\% level of significance.

Table 4

Mean Score for Challenges and Problems Faced when Implementing KM in Case Companies

\begin{tabular}{lcccc}
\hline \multicolumn{1}{c}{$\begin{array}{c}\text { Challenges and problems in KM } \\
\text { implementation }\end{array}$} & \multicolumn{3}{c}{ Mean score } & $\begin{array}{c}\text { ANOVA } \\
\text { Sig. } \mathbf{p}<\mathbf{0 . 0 5}\end{array}$ \\
\cline { 2 - 4 } & Management & Executive & $\begin{array}{c}\text { Non- } \\
\text { Executive }\end{array}$ \\
\hline Too much information & 2.25 & 1.96 & 3.00 & 0.437 \\
Unclear benefits and values of KM & 1.75 & 2.00 & 3.50 & 0.222 \\
Unsystematic KM processes & 2.50 & 2.15 & 2.50 & 0.735 \\
\hline
\end{tabular}

(continued) 


\begin{tabular}{|c|c|c|c|c|}
\hline \multirow{2}{*}{$\begin{array}{l}\text { Challenges and problems in } \mathrm{KM} \\
\text { implementation }\end{array}$} & \multicolumn{3}{|c|}{ Mean score } & \multirow{2}{*}{$\begin{array}{l}\text { ANOVA } \\
\text { Sig. } p<0.05\end{array}$} \\
\hline & Management & Executive & $\begin{array}{c}\text { Non- } \\
\text { Executive }\end{array}$ & \\
\hline $\begin{array}{l}\text { Little or no support from senior } \\
\text { management }\end{array}$ & 1.50 & 1.96 & 1.00 & 0.385 \\
\hline $\begin{array}{l}\text { No rewards or recognition to } \\
\text { appreciate knowledge contributions }\end{array}$ & 1.88 & 2.15 & 2.00 & 0.852 \\
\hline $\begin{array}{l}\text { Resistance from employee to share } \\
\text { knowledge }\end{array}$ & 1.25 & 2.23 & 1.50 & 0.091 \\
\hline $\begin{array}{l}\text { Unavailable technical infrastructure to } \\
\text { support KM }\end{array}$ & 1.38 & 2.15 & 2.50 & 0.259 \\
\hline Inflexible and rigid business processes & 2.13 & 1.92 & 2.50 & 0.745 \\
\hline Employees losing commitment & 1.50 & 1.85 & 3.00 & 0.235 \\
\hline $\begin{array}{l}\text { Underestimating the complexity of } \mathrm{KM} \\
\text { implementation }\end{array}$ & 1.50 & 1.96 & 3.00 & 0.200 \\
\hline Insufficient KM expertise available & 2.25 & 2.15 & 2.50 & 0.915 \\
\hline Knowledge quickly outdated & 1.25 & 2.08 & 2.00 & 0.217 \\
\hline Experts are too busy & 2.13 & 2.15 & 2.00 & 0.984 \\
\hline $\begin{array}{l}\text { Difficulties in maintaining the budget } \\
\text { allocated }\end{array}$ & 1.25 & 2.04 & 3.00 & 0.092 \\
\hline
\end{tabular}

It can be observed from Table 5 that there are five (4) factors with high p values (i.e. these factors have $\mathrm{p}$ values greater than or equivalent to 0.5 ). This shows that the respondents had statistically significant similarity in opinions and agreement on these factors. These factors are: experts are too busy, insufficient KM expertise available, no rewards or recognition to appreciate knowledge contributions, inflexible and rigid business processes, and unsystematic KM processes.

Based on the above discussion, it can be summarized that although KM is being implemented and practised in the case companies, the implementation and practice levels are carried out on a small scale and in a restricted manner. Due to its limited practices in the case companies, the companies face some difficulties in accessing and managing their organizational knowledge for both operational and strategic needs. Thus, it is suggested here in this research that the processes and initiatives of KM are better streamlined and organized to allow for better implementation and practices in the electricity companies in Malaysia. 


\section{KNOWLEDGE AUDIT FRAMEWORK}

The proposed KA framework has four (4) phases (as illustrated in Figure 2) which are adapted from the audit life-cycle by Mohd Drus and Shariff (2011) and is inclusive of an additional phase, phase zero (0). The initial phase, which is phase zero $(0)$, concentrates on the preliminary initiatives that are recommended to be taken by ESI in Malaysia in their initial attempts to introduce KA to the organization. It is hoped that phase zero (0) will help to position the members of the organization into the positive perception and readiness state towards KA initiative in the organization. Phase zero (0) consists of two (2) main activities, which are (a) an in-depth study of the proposed KA framework to better understand its suitability and applicability to the current environment and setup of the electricity company, and (b) communicating the KA initiative organization-wide to gain support and buy-in. These preliminary steps are strongly encouraged to be performed by electricity companies that are quite new or unfamiliar with the KA process. They act as the groundwork of the actual KA exercise to gauge the company's readiness towards it. Upon the successful completion of these preliminary steps, only then can the activities prescribed in the actual KA framework be performed. However, on the subsequent KA exercises conducted, phase zero (0) may not be necessary to be undertaken if the electricity companies have already started to demonstrate acceptance and appreciation of KA.

The phase one (1) of the proposed KA framework is aimed at developing a solid understanding of the business units' environments and operations prior to the actual KA exercise. In the first stage of pre-knowledge audit phase, which is the initiation stage, external factors such as the cost and availability of raw sources (fuel, gas, coal, etc.), as well as governmental policies and regulations are considered. Internal factors such as employees' conditions, management readiness, and technological capacity of the electricity companies, on the other hand, act as the input that inscribe the objectives, scope and direction of the KA exercise that is to be undertaken. The business strategy of an electricity company also provides substantial influence in the KA exercise. The relationship between the internal factors, the external factors and the business strategies of the electricity companies to the initiation stage is depicted by red-colored dash-line arrows. Upon the discovery and understanding of these elements, the establishment stage of the pre-knowledge audit phase will then be executed.

The second phase of the proposed KA framework, or known as during the knowledge audit phase, is where the actual KA conduct is taking place. This is where the current conditions of the business units in terms of the core 
business processes, knowledge environments and knowledge resources are being assessed and appraised by the KA team members. Upon the completion of the analyses, the KA team will propose two (2) types of recommendations to the business units, namely (a) the course of actions to rectify or improve the existing knowledge conditions of the company, and (b) the knowledge strategy (KS) blueprint. As depicted in Figure 2, the recommendation stage is linked with the KS of an electricity company (as indicated by the one-way blue-colored dash-line arrow). This is to indicate that the outcomes of the recommendation stage of the proposed KA framework will determine the suitable KS to be formulated by the electricity companies. The KS formulated can either be an exploration, exploitation or innovation endeavor. The relationship between the KS and the KA in an electricity company also exists in the final phase of the proposed KA framework, where the proposed KS blueprint is being finalized and implemented by the electricity company.

As for the KM implementation in the electricity company, its relationship with the proposed KA framework is evident in three (3) different places. The first relationship is evident in the first phase of the proposed KA framework. In this particular relationship, the KM implementation (if any) in the electricity company provides beneficial inputs in understanding the knowledge environment of the company. Besides that, the KM implementation may also have some influence on the scope and direction of the KA exercise in an electricity company. This is in addition to the external and internal factors and the business strategy of the company (which have been explained earlier). This relationship is indicated by the one-way green-colored dash-line arrow from the KM implementation box to the initiation stage box in Figure 2.

The other relationship between the KM implementation and the proposed KA framework occurs at the second and the third stage of the framework. This relationship is a two-way relationship where the current KM implementation (if any) in the company may have an effect on how the KS and remedial actions will be proposed by the KA team members. On the other hand, if $\mathrm{KM}$ is yet to be implemented by the electricity company, the KS blueprint and remedial actions that are proposed by the KA team will affect the KM implementation of the said company. Thus, this relationship is depicted by a two-way green-colored dash-line arrow in Figure 2.

Table 6 clearly illustrates the objectives, the tasks, the responsible individuals or groups, the level of difficulties in conducting the tasks as well as the key deliverables for each stage of the three (3) phases in the proposed KA framework. The implementation plan will provide electricity companies with an overall perspective of the recommended activities in the proposed framework. It is 
hoped that with the understanding of the detailed activities of the proposed KA framework, electricity companies will not be too demotivated in executing $\mathrm{KA}$ in their organizations. In addition, the implementation plan can also be used as an instrument to explain the KA process to the top management of the electricity companies in an endeavor to obtain their attention and support. Furthermore, the implementation plan can aid the KA team into dividing their tasks between performing the KA activities and the related activities in the electricity companies.

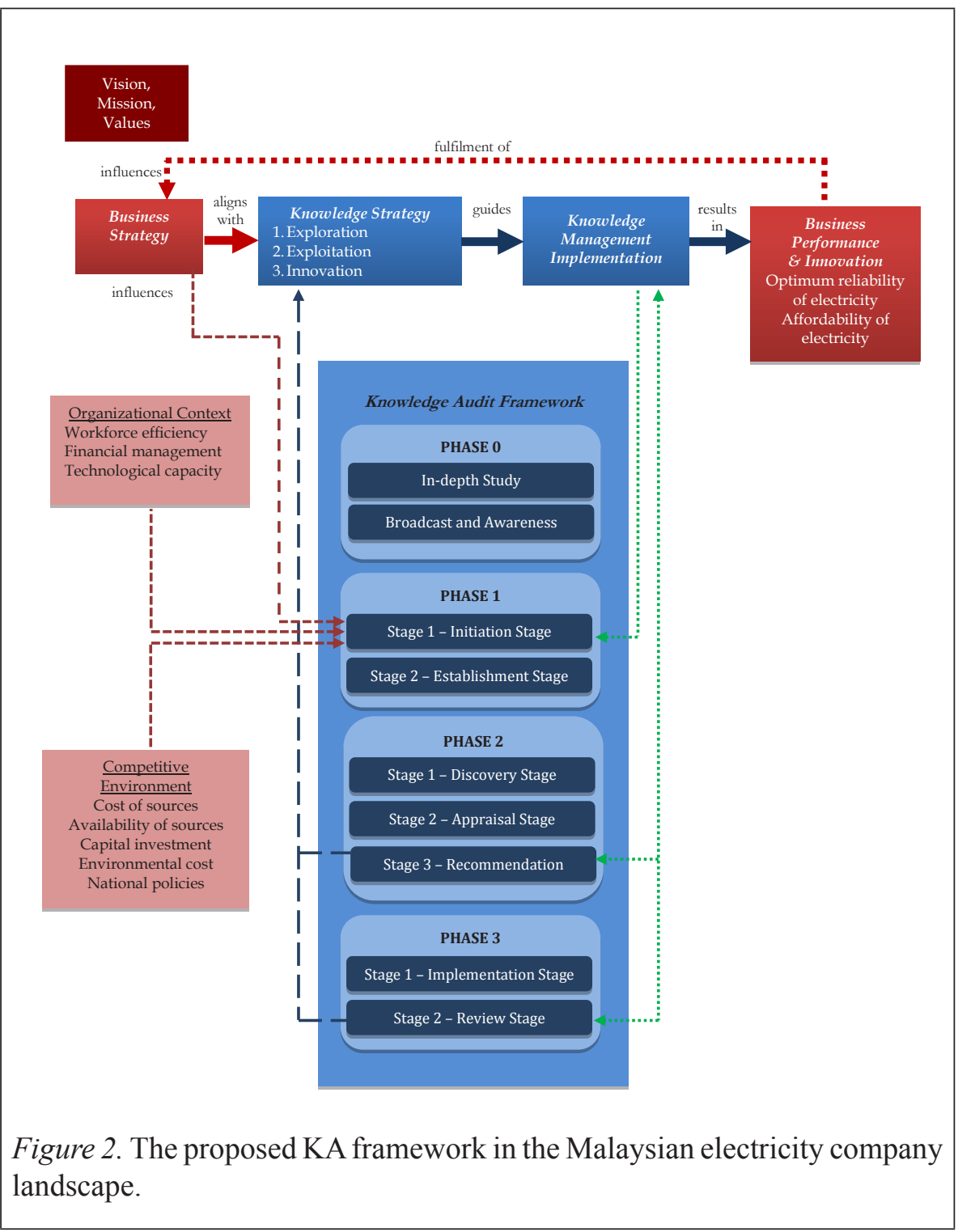




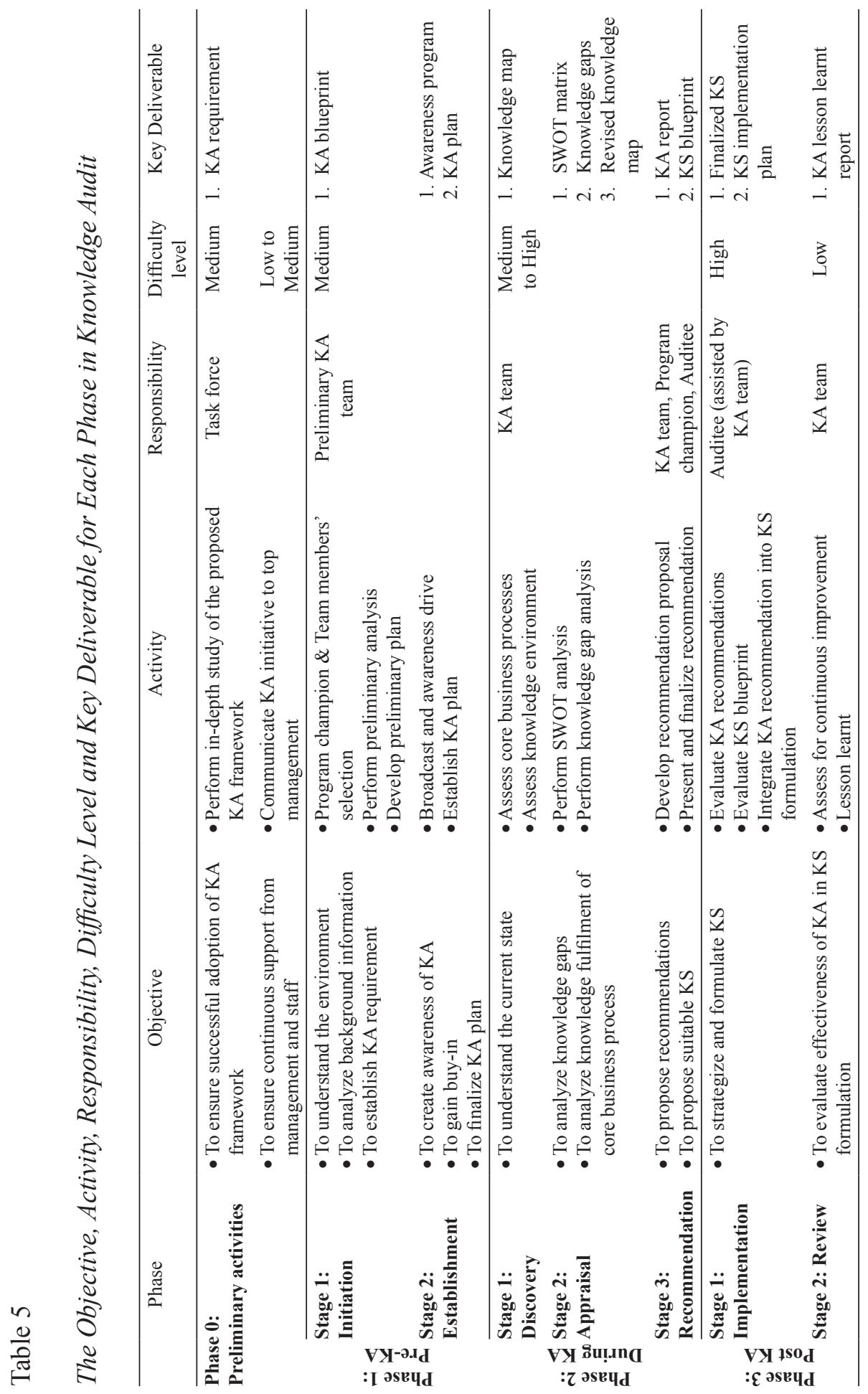


The proposed KA framework which includes elements of continuity by incorporating knowledge strategy (KS) as one of its deliverables whereby the KS blueprint that is deemed applicable is to be adopted by the electricity companies based on their current knowledge environment, conditions and requirements will be recommended. In Shek et al. is (2007) KA framework, $\mathrm{KS}$ is only briefly mentioned without an in-depth explanation and justification for its adoption and implementation. In addition, Gross (2002) does not touch on KS at all in his KA framework. Another pertinent deliverable of the proposed KA framework is the KA lessons learnt. The main purpose of this deliverable is to capture all the challenges and issues that are faced by the KA team members during the KA exercise and how these challenges and issues are being resolved. It is hoped that documenting these issues, challenges and their resolutions, it will help to prevent subsequent KA exercises from experiencing the same problems, and if and when they do happen, the possible resolution as reference is available in the KA lesson learnt. In addition, good practices and methods that are employed by the KA team members during the KA exercise which are deemed to be beneficial may also be included. This will help future KA team members to follow their predecessors' footsteps in conducting the KA exercise which may help to smoothen the audit process. Thus, it can be observed that the proposed KA framework is comprehensive as it covers the process of assessing the current knowledge environment of an electricity company through the proposal of suitable knowledge strategy for electricity companies.

\section{CONCLUSION}

The proposed KA framework benefits the electricity companies as it helps these companies to better understand and appreciate their organizational knowledge and be aware of the gaps or shortcomings that may exist in the current knowledge conditions in their organizations. Thus, it enables electricity companies to find appropriate approaches to improve or rectify their organizational knowledge situations. In addition, the proposed KA framework helps electricity companies to formulate a KS which bestfits their needs and requirements and is in alignment with the business strategies of the companies. Upon the completion of the KA exercise, the electricity companies will have a better understanding of their current knowledge conditions and thus will be able to choose the most suitable type of KS as proposed by this research, namely exploitation, exploration and innovation that better reflects the needs and requirements of their business operations. The proposed KA framework may also be adopted by the other electricity companies in South East Asia whicht have the same business models as the electricity companies in Malaysia, 
such as the Electricity Generating Authority of Thailand (EGAT), Singapore Power (SP) or Perusahaan Listrik Negara (PLN) of Indonesia as well as the players in other utility industries in Malaysia such as telecommunications and water as a point-of-reference in conducting KA exercises, as these industries have a similar nature of operations as the ESI. It is recommended here that all future work of this research nature ought to focus on testing the proposed KA framework in the core business function of an electricity company and review the adoption and implementation of the proposed KS blueprint and rectification course of actions and to further assess whether it results in business process improvements and innovations as well as fulfill the goals of the business strategy of the said company. In summary, the future work of this research type is to assess whether the relationship among the different elements in the business environment of electricity companies in Malaysia, particularly those pertaining to corporate strategy, knowledge strategy, knowledge audit and knowledge management produce the intended results.

\section{REFERENCES}

Bhatt, D. (2000). EFQM - Excellence model and knowledge management implications. Retrieved from http://www.eknowledgecenter.com/articles/ 1010/1010.htm

BenMoussa, C. (2009). Impediments to knowledge management. International Conference on Information Management and Engineering, 322-329. IEEE Computer Society. California: Los Alamitos.

Burnett, S., Illingworth, L., \& Webster, L. (2004). Knowledge auditing and mapping: A pragmatic approach. Knowledge and Process Management, 11(1), 25-37.

Choi, B., Poon, S. K., \& Davis, J. G. (2008). Effects of knowledge management strategy on organisational performance: A complementarity theorybased approach. The International Journal of Management Science, 36 (2), 235-251.

Choy, Y. K. (2005). Energy Demand, Economic Growth, and Energy Efficiency - the Bakun Dam-induced Sustainable Energy Policy revisited. Energy Policy, 33, $679-689$.

Cooper, V. Peszynski, K., \& Molla, A. (2008). Developing a knowledge management strategy: Reflections from an action research project. 16th European Conference on Information Systems (ECIS). 
Du Plessis, M. (2005). Drivers of Knowledge Management in the Corporate Environment. International Journal of Information Management, 25 (3), 193-202.

Economic Planning Unit, Chapter 5 - Developing Malaysia into a knowledge-based economy. The Third Outline Perspective Plan 2001 - 2010. Retrieved from http://www.epu.gov.my/en/the-third-outlineperspective-plan-2001-2010.

Gourova, E., Antonova, A., \& Todorova, Y. (2009). Knowledge audit concepts, processes and practise. WSEAS Transactions of Business and Economics, 6 (12), 605 -619.

Hicks, R. C., Dattero, R., \& Galup, S. D. (2007). A metaphor for knowledge management: explicit islands in a Tacit sea. Journal of Knowledge Management, 11 (1), 5-16.

Hylton, A. (2005). Build Your Knowledge Audit Awareness, Reviewed from http://www.thestep.gr/trainmor/dat/\%7B727027bb-af4a-4b9b-bd876dd1b528132\%7D/article.pdf

Jaafar, A. S. (2002). ICT Utilization and the Information Economy: The Case of Malaysia. Journal of Information and Communication Technology, $1(1), 45-54$.

Jurinjak, I., \& Klicek, B. (2008). Designing a method for knowledge audit in small and medium information technology firms. Proceedings of the 19th Central European Conference on Information and Intelligent Systems, 291-298.

Lauri, S., \& Kyngäs, H. (2005). Developing nursing theories. Dark Oy, Vantaa: Werner Söderström.

Leung, Z. C. S., Cheung, C. F., Chu, K. F., Chan, Y., Lee, W. B., \& Wong, R. Y. W. (2010). Assessing knowledge assets: Knowledge audit of a social service organisation in Hong Kong. Administration in Social Work, 34, 361-383.

Levy, M., Hadar, I., \& Aviv, I. (2009). Enhancing Knowledge-Intensive Business Processes via Knowledge Management Audit. Proceedings of 15th Americas Conference on Information Systems. Paper 85. 
Liebowitz, J., Rubenstein-Montano, B., McCaw, D., Buchwalter, J., \& Browning, C. (2000). The knowledge audit, knowledge and process management. The Journal of Corporate Transformation, 7 (1), 3-10.

Mohamed, A.R., \& Lee, K. T. (2006). Energy for sustainable development in Malaysia: Energy policy and alternative energy. Energy Policy, 34, $2388-2397$.

Mohd Drus, S., \& Shariff, S. S. M. (2011). Analysis of knowledge audit models via life cycle approach. 2011 International Conference on Information Communication and Management (IPCSIT), Singapore.

Nonaka, I. (1994). A dynamic theory of organizational knowledge creation. Organization Science, 5 (1), 14-37.

Ong, H. C., Mahlia, T. M. I., \& Masjuki, H. H (2011). A review on energy scenario and sustainable energy in Malaysia. Renewable and Sustainable Energy Reviews, 15, 639-647.

Patton, M. Q. (2002). Qualitative research and evaluation methods (3rd ed.). California: Sage Publications.

Perez-Soltero, A., Barcelo-Valenzuela, M., Sanchez-Schmitz, G., MartinRubio, F., \& Palma-Mendez, J. T. (2006). Knowledge audit methodology with emphasis on core processes. Proceedings of European and Mediterranean Conference on Information Systems.

Powell, W. W., \& Snellman, K. (2004). The knowledge economy. Annual Review of Sociology, 30, 199-220.

Rahman, B. A., \& Shariff, M. N. M. (2009). Knowledge management initiatives, innovation and GLC performance. Journal of Information and Communication Technology, 8, 15 -27.

Singh, S. P. (2007). What are we managing - knowledge or information. VINE: Journal of Informatics and Knowledge Management Systems, 37 (2), 169-179. 